\title{
Chapter 11 \\ Freedom of Political Communication, Propaganda and the Role of Epistemic Institutions in Cyberspace
}

\author{
Seumas Miller
}

\begin{abstract}
This article provides definitions of fake news, hate speech and propaganda, respectively. These phenomenon are corruptive of the epistemic norms, e.g. to tell the truth. It also elaborates on the right to freedom of communication and its relation both to censoring propaganda and to the role of epistemic institutions, such as a free and independent press and universities. Finally, it discusses the general problem of countering political propaganda in cyberspace and argues, firstly, that there is an important role for epistemic institutions in this regard and secondly, that social media platforms need to be redesigned since, as they stand and notwithstanding the benefits which they provide, they are a large part of the problem.
\end{abstract}

Keywords Applied ethics - Epistemic institutions - Epistemic norms · Fake news · Hate speech $\cdot$ Knowledge $\cdot$ Objectivity $\cdot$ Propaganda $\cdot$ Social media

\subsection{Introduction}

Social media platforms, such as Facebook and Twitter, are used by billions of communicators worldwide, as are search engines such as Google. The advent of these tech giants, or at least of the technology upon which they rely, has enabled the moral right to communication to be exercised on a scale hitherto undreamt of and, as a consequence, led to unprecedented flows of information and opinion, globally as well as locally. However, these developments have gone hand in hand with an exponential increase in the spread of fake news, hate speech and propaganda (Cocking

\footnotetext{
S. Miller $(\bowtie)$

Charles Sturt University, Canberra, Australia

TU Delft, The Hague, The Netherlands

University of Oxford, Oxford, UK

e-mail: semiller@csu.edu.au 
and van den Hoven 2018; see also Chap. 12). Of particular relevance to this article on political communication, the advent of the tech giants has enabled extremist political groups, such as Islamic State to flourish, facilitated interference in the democratic process by foreign powers (e.g. in the US presidential elections by Russia), and turbo-charged virulent politically motivated hate speech leading, in some instances, to murder and mayhem, as in the recent case of attacks on Rohingya Muslims following hate speech on Facebook that emanated from the Myanmar military.

Recent revelations concerning data firm Cambridge Analytica's illegitimate use of the data of millions of Facebook users highlight the ethical issues arising from the use of machine learning techniques in relation to social media for political purposes. Cambridge Analytica is, or was - the revelations brought about its demisea firm that used machine learning processes to try to influence elections in the US and elsewhere by, for instance, targeting 'vulnerable' voters in marginal seats with political advertising (Grassegger and Krogerus 2016). Of course, there is nothing new about political candidates and parties employing firms to engage in political advertising on their behalf, but if a data firm has access to the personal information of millions of voters, and is skilled in the use of machine learning techniques, then it can develop detailed, fine-grained voter profiles that enable political actors to reach a whole new level of manipulative influence over voters. The ethical consequences are potentially far reaching. One set of ethical issues pertains to privacy and confidentiality; illegitimate access on the part of Cambridge Analytica to private information and, in the case of Russian hackers hacking into the democratic party's emails, to confidentiality. Another set of ethical issues pertains to institutional corruption; corruption of the democratic process. A further set of ethical issues pertains to national security; the use of machine learning techniques by foreign powers, such as Russia, to favour one candidate over another in the service of their own political agenda, e.g. to sow discord in liberal democratic polities. Such manipulative political influence over users of social media utilising a combination of new technological tools, such as machine learning, and psychologically based, manipulative marketing techniques raises more directly the emerging ethical issue of the tension in cyberspace between freedom of communication, on the one hand, and the need to restrict certain forms of political propaganda on the other.

It is agreed by all that the dissemination of fake news, hate speech and extremist propaganda on the Internet and on social media in particular is a bad thing and should be curtailed, if not prohibited, albeit giving effect to this is easier said than done. However, a host of difficult practical ethical problems arise at this point. Who ought to decide what is fake news and what is fact-the tech giants themselves? Who ought to decide what counts as hate speech, and on the basis of what criteria? Should all political propaganda be prohibited and, if not, which should be prohibited, which permitted and on what basis? Doubtless, Islamic State's YouTube video clips of beheadings and incitements to murder should be prohibited, but what of the propaganda disseminated by right wing groups who might not advocate the overthrow of the state or the murder of innocents but, nevertheless, do disseminate political perspectives at odds with liberal democratic values, such as tolerance of 
minorities, and in doing so rely heavily on false claims, half-truths and racial and other long standing prejudices-thereby undermining liberal democratic institutions, including epistemic institutions.

What do I mean by epistemic institutions (Miller 2010)? The term 'episteme' refers, of course, to knowledge. Therefore, epistemic institutions are those institutions that have as a principal institutional purpose the acquisition and/or dissemination of knowledge (understood broadly so as to include factual knowledge, reasoning processes such as induction and deduction, evidence-backed economic, political and ethical perspectives, and understanding). Accordingly, epistemic institutions include schools, universities and media organisations responsible for news/comment. They also include private or government research laboratories, think tanks and, for that matter, intelligence agencies.

These practical ethical questions mentioned above presuppose answers to some more fundamental theoretical questions. For instance, can the distinction between politically motivated fake news, hate speech and propaganda, on the one hand, and, on the other hand, factual and other objective claims and perspectives actually be sustained? What is the nature and extent of the moral right of freedom of communication? Who ought to be the decision-makers in relation to determining what is fake news, hate speech and political propaganda in cyberspace. More specifically, who ought to be the decision-makers in relation to determining when such communications ought to be prohibited?

In this article, my concern is with countering politically motivated fake news, hate speech and propaganda while respecting the moral right to freedom of communication. In the first section, I offer definitions of fake news, hate speech and propaganda respectively. As we shall see, these phenomena have at least one important feature in common; they are not truth-aiming (in a certain sense). In the second section, I elaborate on the right to freedom of communication and its relation to epistemic institutions. In the third and final section, I discuss the general problem of countering political propaganda in cyberspace and the role of epistemic institutions and social media platforms in this enterprise.

\subsection{Fake News, Hate Speech and Propaganda}

The definition of fake news is contested and, therefore, the following definition is necessarily somewhat stipulative (Lynch 2016a). News by definition purports to be true or, in the case of visual images and the like, purports to be an accurate representation of reality, even if it is in fact false. However, news items are frequently disseminated on the Internet by persons who do not endorse them; indeed, on occasion, by persons who explicitly state at a later time that they are false. Here I use the term 'fake news' to refer to news that is in fact false and not believed by its originatoras opposed to subsequent disseminators - to be true. Accordingly, on this definition, news that is false and believed to be false by its originator is fake news, but so is news that is false and neither believed nor disbelieved by its originator is to be true. 
This is because news by definition - and whether it is in fact true or false-purports to be true. Thus, whatever its originator believes or does not believe, he or she presents the news item as being true.

Fake news is problematic for at least two reasons. Firstly, it is false and yet, given the communicative reach of the Internet, and of social media - and the use of automated dissemination techniques, e.g. bots-it is likely to be believed by many, even if disbelieved by many others (or, at least, their beliefs are suspended). I note that somewhat paradoxically the credibility of fake news on social media platforms, notably Facebook, is enhanced by the co-presence on these platforms of objective news emanating from high quality news outlets, such as the New York Times. Secondly, especially in the case of an ongoing series of mutually supportive, politically motivated, fake news items, there are likely to be untoward political consequences arising from large numbers of people believing such news items, including potentially the undermining of democratic processes that rely on voters making judgments based on facts rather than falsehoods.

It is sometimes suggested that ultimately there is no important distinction between fake news and factual news and, as a corollary, politicians, academics, news media and other disseminators cannot provide objective communicative content of high quality since the notion of such objective truth or of a fact of the matter independent of representations is itself meaningless or hopelessly naïve; accordingly, one media or other report cannot be of higher quality than another by virtue of being correct or more accurate or more balanced. It is further suggested that the reasons for this are manifold, and they include: the fact that communicative content is a representation and, as such, always reflects a standpoint; that mechanisms of media communication necessarily mediate, and therefore distort; that quality is simply in the eye of the beholder; and so on. There is not the space to deal with all these kinds of arguments in detail, though it is not difficult to show that they do not demonstrate the strong position they are intended to (Bok 1978). Suffice it to say here that the notion that we cannot aim at truth, and on occasion approximate to it, and the notion that every piece of analysis and comment is as good as every other, is self-defeating and, if accepted, would render communication pointless. It is a presupposition of communication in general, including both linguistic communication and visual representation, that there is a truth to be communicated or some fact of the matter to be represented, and that on many occasions this is achieved. If this were not so, communication of news would be rendered pointless and cease to take place. Thus, it would be pointless, because not objectively true, to report that on 9/11 two planes were flown by terrorists into the Twin Towers building in New York City killing some 3000 people. Likewise, it would be pointless to show footage of the planes flying into the towers and the subsequent collapse of the towers; pointless because (allegedly) there was no fact of the matter. Moreover, it is a presupposition of comment and analysis that not every piece of analysis and comment is as good as every other one, since there is always as least one which is regarded by the communicator as inferior, namely that which is the negation of the one put forward, e.g. that terrorists did not fly and planes into Twin Towers and did not kill anyone. 
While the distinction between fake news and factual claims is relatively clearcut, notwithstanding claims to the contrary, distinctions, firstly, between politically motivated hate speech and strident pejorative criticism, and, secondly, between, political propaganda and political comment/opinion, are more problematic.

The definition of hate speech is contested. Let us, assume, however, that it is speech that incites hatred against some group (Waldron 2012)—or, at least, is intended to do so and has some reasonable chance of doing so. Accordingly, hate speech is to be distinguished from strident pejorative criticism insofar as the latter is truth-aiming, i.e. has truth as an end in itself. By contrast, hate speech is not truthaiming in this sense; the truth is only of interest in so far as it can serve to incite hatred.

Hate speech does not necessarily incite violence or other serious crimes, albeit these may well be longer term, indirect consequences of hate speech. The hate speech of interest to us here is politically motivated hate speech; speech that incites hatred against a target group and is performed in order to serve some political purpose, e.g. a right-wing politician seeking to get elected by vilifying immigrants belonging to a minority ethnic group. Naturally, politically motivated hate speech, often features abusive language, and manifestly incites hatred against the target group. However, sometimes it is couched in moderate language and consists in advocating particular policies ostensibly based on facts ('facts' which turn out to be false or highly misleading). In the latter cases context is all important if the speech in question is properly to be regarded as hate speech. Consider, for instance, a rightwing politician's speech advocating that immigrants from a certain racial group should be sent back to their homeland and that there should be a ban on any further immigrants from that group, on the grounds that, as he falsely claims, the immigrants in question are mostly criminals and/or welfare recipients. Suppose this speech is disseminated via social media and on a targeted basis to members of an audience likely to be receptive to these views in part because of their pre-existing prejudice. The speech is racially discriminatory and, given its pattern of dissemination and its ultimate intention, i.e. to incite racist sentiment in the service of a political agenda (let us assume), it arguably constitutes hate speech.

In the light of this definition of hate speech as speech intended to incite hatred, and having a reasonable chance of doing so, it is clear that politically motivated hate speech is potentially harmful not only to individual and groups who are the object of its attack, and not only because it is likely to be false, but because it is likely to sow discord in a liberal democratic polity and, for that matter, in authoritarian states. As is the case with fake news, hate speech in cyberspace is especially problematic, given the communicative reach of the Internet and social media platforms in particular.

Political propaganda is, I suggest, communication in the service of a political ideology (Ellul 1973). Therefore, political ideology is the more fundamental concept. Accordingly, we need a serviceable account of political ideology and one that enables a distinction to be maintained between ideology, on the one hand, and the more generic notion of systems of political ideas, on the other.

Firstly, it is important to note that in order for something to be an ideology it must comprise a set of systematically connected beliefs, assumptions or claims. 
Moreover, this systematically connected set of beliefs or claims must if it is an ideology be susceptible of instantiation; and if it is instantiated it must be instantiated in the minds of a group of people. Such a group must constitute a community (of sorts) and not simply a set of unrelated individuals. The notion of an (instantiated) ideology, then, is the notion of a shared set of beliefs and claims. Furthermore, the key constitutive elements of the system are beliefs and claims cannot be too strongly emphasised, since it is sometimes supposed that the key constitutive elements are actions, at other times appearances, and at still other times that these elements are words or concepts. However, an ideology cannot consist of actions, social practices and the like per se since unlike beliefs or claims, actions are not about the world and are not true or false; but it is a constitutive feature of an ideology that it be about the world, and that it be true or (more likely) false. Nor can an ideology comprise appearances per se, even though the way the world appears to be may bring about false beliefs and indeed ideological beliefs. Here a perceptual analogy may be useful. A stick placed in water has the appearance of being bent and may cause the perceiver to believe that it is in fact bent. Yet from the fact that the world appears to a subject to be a certain way it does not follow that the subject believes that the world is the way it appears to be. We do not, for example, believe that the stick is bent, although it certainly appears to us to be bent. However, if appearances are not necessarily accepted as true by a subject then they cannot be constitutive of ideologies, for if someone adopts an ideology then the person accepts its content as being true. Again, it is surely clear that it is only beliefs and claims, as opposed to unitary items such as words or concepts, that constitute commitments to this or that view of the world, and as such can be true or false. By contrast, words and concepts as such do not constitute such commitments and make no truth claims. Thus, the word 'unicorn' is consistent with there being or not being unicorns; however, the belief 'there are unicorns' is a commitment to the world being a certain way and is true if the world is that way and false if it is not.

Secondly, I suggest that for any systematically connected set of shared beliefs to count as an ideology it must have a certain kind of origin. In particular, the existence of the ideology cannot ultimately be caused by the world being as the ideology says it is. Thus a particular systematically connected set of beliefs (say liberalism) would qualify as an ideology on our definition if it were brought into existence not by the world being as liberalism says it is, but rather was fashioned as an expedient account of things by the economically ascendant classes.

Thirdly, I suggest that to count as a political ideology, a set of beliefs must serve some kind of political purpose. It might, for example, have the purpose of undermining or, alternatively, of preserving the political status quo.

Finally, it should be noted that there is a high probability that an ideology will be false, given that its causal origin cannot be the world being the way the ideology says it is, and given that it must serve some or other political purpose. That said, it is important to keep in mind that political ideologies typically consist in part in truths, as well as falsehoods and half truths, and rely in part on legitimate grievances. If not, they are likely to have little or no credibility. 
However, core or constitutive elements of a political ideology are likely to be false or fanciful, e.g. the classless society, the Caliphate. Moreover, the propagation of an ideology relies on falsehoods, half-truths and hate speech. Modern propaganda is likely to rely on a suite of psychologically based, manipulative marketing techniques and fake news disseminated on the Internet. Aside from the constitutively ideological components of an ideology, i.e., its content, ideology impacts itself causally on communication and thought, by way of permeation, by implication, and by being presupposed. Accordingly, and notwithstanding what was claimed above, actions, practices, appearances and so on can be used to convey ideological content.

Sometimes processes of permeation, implication and presupposition enable the ideology to influence while going undetected. Consider an advertisement consisting of a video clip of a well-dressed, handsome man ostentatiously smoking an identifiable brand of cigarette, standing next to an expensive car, and making the statement 'That is a fine car'. Here, there may be an (as it were) non-political-ideological core belief: the conviction that in virtue of its being mechanically sound and fuelefficient, the car is fine. However in addition to this non-ideological core belief, and overlaying it, may be ideological beliefs, such as the belief that the car is fine, not simply in virtue of being mechanically sound but also in virtue of being socially prestigious because expensive. Here a core of non-ideological meaning is permeated by ideological meaning: in effect, a consumerist ideology is being sold. In addition, of course, there is the implication that smoking this particular brand of cigarette goes hand in glove with having prestige.

A further kind of example entails the notion of a presupposition as well as implication, albeit there is no attempt to conceal the ideological message. Consider for instance the statement, 'all Crusaders are mortal' uttered in the context of an extremist jihadist diatribe. Here there is a crude ideology presupposed, viz. that the world is divided up into Christians who are loathsome and Muslims who are not. In addition, the reference to mortality implies that Christians can and should be killed.

A final important point needs to be kept in mind. Propaganda on its own has little political effect. If it is to undermine, for instance, a liberal democracy it needs to be a component of an integrated package comprising the existence of a felt grievance against some group, such as injustice suffered at the hands of the political elite, a technological means for wide dissemination, (e.g. printed matter, social media) and, at least in conflict situations, some form of kinetic capacity (e.g. armaments), and strategy (e.g. terrorism) (Ingram 2016). Needless to say, as is the case with fake news and hate speech, the unprecedented communicative reach afforded by the Internet and social media platforms to propagandists have greatly increased the potential impact of political propaganda. 


\subsection{Freedom of Communication, Truth and Liberal Democracy}

Notwithstanding the individual, collective and institutional harms caused by politically motivated fake news, hate speech and propaganda-not to mention their inherent epistemic and moral undesirability - there are good reasons not to enact laws to prohibit them entirely, although these reasons are consistent with placing some legal restrictions on them. For instance, most would agree that there should be laws against incitements to violence. Naturally, it does not follow from this that there should not be individual, collective and, indeed, institutionally based opposition to fake news, hate speech and propaganda. The historically most important reason for not enacting laws to prohibit fake news, hate speech and propaganda is the moral right to freedom of communication (Schauer 1981).

There are two especially salient arguments for freedom of communication and, relatedly, freedom of intellectual inquiry, the first associated with the English philosopher John Stuart Mill (1869), the second (loosely) associated with the German philosopher Immanuel Kant (1956). (I do not mean to imply that these arguments are the only ones advanced by these philosophers, much less that the versions of them I propound below are precise renderings of the work of these philosophers.)

According to Mill, new knowledge will only emerge in a free marketplace of ideas. If certain ideas are prevented from being investigated or communicated then the truth is not likely to emerge, since those suppressed ideas may in fact be the true ones. I note that the notion of a market place in play here might need to be somewhat loosely construed so that, for instance, Wikipedia might be understood as a market place in so far as there are no barriers to participation by adding or correcting information, although there are no buyers and sellers in the conventional sense. I take it that Wikipedia involves a form of collective epistemic action or, as I term it, joint epistemic action (Miller 2018). It relies on the epistemic (knowledge) contribution of multiple actors.

Let us look more closely at this argument, restricting ourselves to political ideas in the sense of politically relevant factual claims, hypotheses, unsubstantiated claims, interpretations and theories, the epistemic resolution of which call for occasionally complex processes of reasoning and justification to be undertaken in a public forum such as, in recent times, the Internet and social media platforms. Here, Mill appears to rely on a distinction between rational inquiry and justification on the one hand - a possibly solitary activity — and freedom of communication on the other.

This argument needs to be unpacked (Miller 2000). I suggest the following rendering of it.

(1) Freedom of communication is necessary for rational inquiry.

(2) Rational inquiry is necessary for knowledge.

Therefore: (3) Freedom of communication is necessary for knowledge.

The argument is valid and premise (2) is plausible in relation to the sort of knowledge at issue here. What of premise (1)? 
The justification for (1) is evidently that rational inquiry requires: (i) a number of diverse views or perspectives (possessed by different persons and different interest groups) and; (ii) a substantial amount of diverse evidence for/against these views (available from different sources). Moreover, (iii) regarding (i) and (ii), there is no single (a) infallible and (b) reliable authority.

Note that Mill's argument for freedom of inquiry - understood as rational inquiry in a context of freedom of communication-is instrumentalist or means/end in its form. The claim is not that freedom of inquiry is good in itself, but rather that it is a means to another good, namely knowledge and, it should be added, the knowledge of interest to us here and, for that matter, to Mill is collective knowledge generated by joint epistemic action. The notion of collective knowledge in play here is (roughly speaking) that of knowledge shared among members of a population, be the population a polity, a global audience or, for that matter, an academic community (which is probably a segmented global community). (It is then an open question-as far as Mill's argument is concerned-whether or not knowledge is an intrinsic good, or merely a means to some other good. By contrast, I assume that knowledge is an intrinsic good.) To this extent, the moral weight to be attached to freedom of inquiry is weaker than it would be by the lights of an argument, which accorded freedom of inquiry the status of an intrinsic good or fundamental moral right.

The second argument for freedom of inquiry is not inconsistent with the first but is nevertheless quite different. Specifically, it accords freedom of inquiry greater moral weight by treating it as having the status of a fundamental moral right. This second argument-or at least my own neo-Kantian rendering of it-relies on a wider sense of freedom of intellectual inquiry, one embracing not only freedom of thought and reasoning but also freedom of communication and discussion. The argument begins with the premise that freedom of intellectual inquiry thus understood is a basic, as opposed to derived, moral right. Here the term 'intellectual' is intended to be taken in its original Latin-based sense of pertaining to understanding, as opposed to its modern rarefied sense of pertaining to those matters that can only be understood by experts or 'intellectuals'. Intellectual inquiry is a human practice that should not be the preserve only of academics and other experts. This is not to say that academics and others with specialist or more developed levels of understanding ought not to be accorded due respect as epistemic authorities. Climate scientists are a case in point.

Thus conceived, freedom of intellectual inquiry is not an individual right of the ordinary kind. Although it is a right which attaches to individuals, as opposed to groups per se, it is not a right which an individual could exercise by him/herself. Communication, discussion and intersubjective methods of testing are social, or at least interpersonal, activities. However, it is important to stress that they are not activities, which are necessarily relativized to certain designated social groups. In principle, intellectual interaction can and ought to be allowed to take place between individuals in interpersonal and communal, including on-line, settings irrespective of whether they belong to the same social, ethnic or political group. In short, freedom of intellectual inquiry, or at least its constituent elements, is a basic moral right. Note that being a basic moral right it can, at least in principle, override collective interests 
and goals, including national economic interests and goals. Hence, the dilemmas that can arise between, for instance, security and freedom of communication.

If freedom of intellectual inquiry is a basic moral right then, like other basic moral rights such as the right to life and to freedom of the person, it is a right that all humans possess and it is a right that should be protected in liberal democracies in particular. Here, we need to be clearer on the relationship between the basic moral right to freely engage in intellectual inquiry on the one hand, and knowledge or truth on the other.

The term 'knowledge', as used in this context, embraces not only information but also understanding. Note also that in order to come to have knowledge in this sense, one must possess rational capacities, i.e. capacities that enable not only the acquisition of certain kinds of information, e.g. via a Google search, but especially the development of understanding. Here the term 'rational' is broadly construed. It is not, for example, restricted to deductive and inductive reasoning. This point holds irrespective of whether the communicative context is offline or online, the coffeehouse or Twitter, and notwithstanding the advantages and disadvantages - and ultimate intellectual upsides and downsides (Lynch 2016b) —of some of these modes of communication over others, e.g. lengthy single speeches to a small audience versus brief tweets to thousands.

Freedom of intellectual inquiry and knowledge, in this extended sense of knowledge, are not simply related as means to end, but also conceptually. To freely inquire is to seek the truth by reasoning. Truth is not an external contingently connected end which some inquiries might be directed towards if the inquirer happened to have an interest in truth, rather than, say, an interest in falsity or (a la Derrida) playfulness. Rather, truth is internally connected to intellectual inquiry. An intellectual inquiry, which did not aim at the truth, would not be an intellectual inquiry, or at least would be defective qua intellectual inquiry. Moreover, here aiming at truth is aiming at truth as an end in itself. (This is not inconsistent with also aiming at truth as a means to some other end.) In other words, an alleged intellectual inquiry which only aimed at truth as a means to some other end would not be an intellectual inquiry or would be defective qua intellectual inquiry, since for such a pseudo-inquirer truth would not be internal to his/her activity. Such a pseudo-inquirer is prepared to abandonand indeed would have in fact abandoned-truth-aiming if, for example, it turns out, or if it had turned out, that the means to his or her end was not after all truth, but rather falsity.

Furthermore, to engage in free intellectual inquiry in my extended sense involving communication with, and testing by, others, is to freely seek the truth by reasoning with others. Intellectual inquiry in this sense is not exclusively the activity of a solitary individual. Moreover, here reasoning is broadly construed to embrace highly abstract formal deductive reasoning at one end of the spectrum and informal (including literary) interpretation and speculation at the other. Furthermore, it embraces ordinary political discourse among non-specialists as well as technical discourse among experts, and discourse attempting to bridge these divides, e.g. between scientists and ordinary citizens on climate change. 
There are, of course, methods of acquiring knowledge which do not necessarily, or even in fact, involve free inquiry, e.g. my knowledge that I have a toothache, or my knowledge that the object currently in the foreground of my visual field is a table, but these taken in themselves are relatively unimportant items of knowledge as far as public discourse is concerned, and certainly as far as epistemic institutions such as the press and universities are concerned. (Obviously, other items of knowledge of the same species can be very important in the context of some intellectual inquiry e.g. an inquiry into whether a recently developed drug eases pain or an inquiry into ordinary perception.)

Given that freedom of intellectual inquiry is a basic moral right, and given the above described relationship between intellectual inquiry and truth (or knowledge), we can now present our second argument in relation to freedom of intellectual inquiry (Miller 2000). This argument in effect seeks to recast the notion of freedom of intellectual inquiry in order to bring out the potential significance for liberal democratic polities, in particular, of the Kantian claim that freedom of intellectual inquiry is a basic moral right.

(1) Freedom of intellectual inquiry is a basic moral right.

(2) Freedom of intellectual inquiry is (principally) freedom to seek the truth by reasoning with others.

(3) Freedom to seek the truth by reasoning with others is a basic moral right.

Our discussion has yielded the following plausible propositions. First, the kind of knowledge in question is typically attained by reasoning with others (whether conducted offline or on-line, whether in the coffee house or via Twitter etc.). Second, to engage in free intellectual inquiry is to seek truth (or knowledge) for its own sake. Third, freely seeking the truth (or knowledge) for its own sake, and by reasoning with others, is a basic moral right.

Let us grant the existence of a basic moral right to freely pursue the truth by reasoning with others. The political implications of this are threefold. Firstly, liberal democracies, in particular, need to ensure that this moral right of members of the citizenry is respected, indeed cultivated. As Mill stressed, the ability to exercise this right, and the habit of exercising it, are preconditions of liberal democracy. Secondly, liberal democracies need to ensure that this right is institutionally embedded in epistemic institutions in particular. For instance, the exercise of the moral right to freely pursue the truth by reasoning with others is a central feature of universities (Miller 2010). Naturally, the truths in question are sometimes ones difficult to acquire without intellectual training of various kinds, e.g. empirical methods. Again, the moral right to pursue the truth by reasoning with others is a central feature of media organisations functioning as the so-called Fourth Estate (Miller 2010) or, at the least, ought to be a central feature of these organisations even if it is often not (Gore 2007). Naturally, the truths in question pertain to matters of public interest and are often subject to political contestation. Thirdly, liberal democracies need to ensure that public discourse, including in cyberspace, is conducted in accordance with the conventions in part constitutive of the exercise of the moral right to freely 
pursue the truth by reasoning with others, e.g. the convention to aim at the truth, conventions governing evidence collection and analysis. Here, there is a need for qualifications when the communication in question is understood to be of an informal or casual kind, e.g. between Facebook friends, or when the communicators are, say, children. I note that fake news, hate speech and propaganda flout these conventions - although they are parasitic on them (see below) - and are antithetical to the proper exercise of the right itself (the right to freely pursue the truth with others) . Accordingly, the question that now arises is how political propaganda (including politically motivated fake news and hate speech) is to be countered.

\subsection{Epistemic Institutions, Market-Based Social Media Platforms and Combating Propaganda}

Effectively countering political propaganda-including political propaganda impregnated with fake news and hate speech-is a complex undertaking. For one thing, as noted above, determining what is propaganda and what is not is problematic, especially given that, as shown above, non-ideological content often only implies or is permeated by ideology. For another thing, it is inconsistent with the liberal democratic value of freedom of communication to prohibit all propaganda, all fake news or even all hate speech. Moreover, as is to be expected, different liberal democracies take a different view on where to draw the line here. The US does not prohibit hate speech (unless it directly incites serious crimes such as violence) whereas many EU jurisdictions do (Waldron 2012). This is, of course, not to say that propaganda might not be curtailed (with necessarily being prohibited), as is the case with advertising. Cigarette advertising, for instance, is curtailed without being prohibited in many jurisdictions, e.g. no cigarette ads on TV or on sites accessed by children.

However, even if the legal issues could be contended with (on the basis, in part, of cogent ethical analysis) and agreed to nationally, and perhaps globally — since international regulations might be required for certain platforms and content - there remains the enforcement problem. Consider extremist jihadist propaganda that incites violence and, as such, is prohibited. According to J. M. Berger, for instance, extremist jihadist propaganda has three dimensions: content; dissemination methods; identity (Berger 2017). Accordingly, in the case of extremist jihadist propaganda, social media sites can be quickly taken down, undermining that particular dissemination method. On the other hand, terrorist attacks themselves continue to be widely reported in the local and global media, thereby giving oxygen to terrorists. Moreover, there are more sophisticated and, potentially, more effective methods of dissemination of propaganda. For example, the targeting of 'vulnerable' groups by state actors such as Russia. As mentioned above, these can make use of large data banks and machine learning techniques to build profiles and target the vulnerable. Such methods are not so easy to counter, although providing adequate 
protection of personal information held by social media companies, such as Facebook, would be a good start.

Directly countering content with counter-messaging, e.g. counter-messaging espousing liberal democratic values, may have a limited effect on those susceptible to propaganda, whether fundamentalist Muslims or those with extreme right views. After all, it is these groups' felt alienation from liberal democracy that is in part the source of the problem. Successful propaganda, as was suggested above, is always anchored in part in reality (but is also vulnerable to the communication of reality, i.e. facts inconsistent with its content-inconvenient truth" [Gore 2007]). Accordingly, there is likely to be a need to address felt grievances, at least to the extent that they are justified, e.g. if in part based on economic injustice. Naturally, propaganda can be countered by counter-propaganda, disinformation campaigns and the like, as frequently happens in war-time, for instance. However, there is something inherently morally problematic in liberal democracies eschewing a commitment to truth (notably facts), evidence-based rational inquiry and open discussion, in favour of propaganda, i.e. fake news, half-truths, manipulation, hate speech(?) etc. Moreover, this strategy might ultimately be counter-productive and simply end up devaluing the liberal democratic currency.

What of identity? Certainly an appeal to national, religious, ethnic, racial, class or other identity and an attempt to drive a wedge between 'them' and 'us' is an important feature of political propaganda. The propaganda in question might or might be unlawful, depending on the nature of it and the jurisdiction in which it is disseminated. Given legal limitations or enforcement problems what is the way forward here? Naturally, if a polity has processes and pursues policies that are just (both procedurally and substantively), inclusive (e.g. of marginalised groups) and effective (i.e. have beneficial outcomes) then this will mitigate the harms of identity focused propaganda. However, as is the case with other strategies, this strategy while necessary is not sufficient. It is not a silver bullet. Moreover, when the identities in question are national identities and the 'us-them' wedge is being driven by their own governments, e.g. the Russian government in the Baltic states, the Chinese government in respect of foreign states who oppose its policies in the South China Sea, or the United States under the Trump administration's 'America First' policy, then this strategy is unlikely to succeed even if it can be implemented to some extent.

In the context of the legal limitations and/or enforcement problems confronting the enterprise of countering political propaganda (including politically motivated fake news and hate speech), and assuming that counter-propaganda, disinformation and the like are not a morally acceptable option, I want to suggest a different strategy; a strategy which should be seen as complementary to the other strategies already mentioned. In doing so, I draw attention to three somewhat neglected, related, underlying conditions that facilitate political propaganda, namely: (1) the strength of epistemic norms in a population targeted by propaganda; (2) the intellectual health of the epistemic institutions in that population, and; (3) their degree of embeddedness in, and influence on, the population that hosts them.

I note at the outset the importance of maintaining not only the distinction insisted upon above between propaganda and knowledge acquisition/dissemination 
(typically a species of joint epistemic action), but also between knowledge acquisition/dissemination and entertainment, e.g. soap operas, cartoons. The latter does not generally purport to be true. However, the emergence in recent decades of infotainment, including in cyberspace, is corrosive of this distinction; a point I cannot pursue further here. While insisting on the distinction between propaganda and knowledge acquisition/dissemination, it is also important to draw attention to a central aspect of their relationship; propaganda is parasitic on knowledge acquisition/ dissemination and the epistemic norms that underpin it. Fake news, for instance, purports to be true; otherwise, it would have little effect. However, while pretending to comply with the epistemic norm of aiming at the truth, it flouts it; it is not required by its originator to be true and, indeed, its originator often knows it is false-it is a lie.

As with many parasites, propaganda undermines the health of its host while simultaneously relying on the continued existence of its host. Accordingly, propaganda is a species of corruption: institutional corruption (Miller 2017). If successful, propaganda corrupts epistemic norms within a population and may also corrupt epistemic institutions, notably media organisations responsible for news/comment which lack independence from an authoritarian government or which are subject to powerful and pervasive financial pressures tending to cause them to espouse, for instance, a virulent form of capitalist ideology. On the other hand, propaganda, being parasitic on epistemic norms, is susceptible to criticism for failing to live up to the epistemic and, importantly, moral standards it purports to be complying with. It purports to be true and hence is discredited when shown to be false. Propagandists fail to meet moral standards not simply because they fail to comply with epistemic standards by being incorrect or insufficiently attentive to the evidence, but because they are dishonest; they pretend to be aiming at the truth while actually telling lies. Accordingly, propagandists can be criticised not only for being incorrect, but also for being dishonest; indeed, for being corrupt. The charge of corruption is more likely to generate moral disapproval and, ultimately, rejection among members of a population than are purely epistemic offences.

In a liberal democratic polity, epistemic institutions, notably the free and independent press, and schools and universities, have a key role in combating propaganda, or so I suggest. Epistemic institutions, such as schools and universities, have a key role in building resilience to propaganda, whether it be on-line or off-line propaganda, by cultivating the skills and habits of rational inquiry and, relatedly, the development of well-informed, rationally defensible, political perspectives among children and adults. Moreover, epistemic institutions, such as a free and independent press and universities, have a key role in not only ensuring that the citizenry is reflective and well informed, but also in helping to ensure that public discourse, whether on-line or off-line, is conducted in accordance with the epistemic norms constitutive of free and open rational inquiry; consistent with the proper exercise of the right to freely pursue the truth by reasoning with others. For instance, experienced investigative journalists based in well-resourced newspapers, such as the New York Times, are the source of much of the important news to enable informed opinions on the part of voters. Moreover, those responsible for politically motivated fake 
news, hate speech and, more generally, propaganda can be held to account by a free and independent press. Consider, in this connection the British Broadcasting Commission (BBC). The BBC is both independent of government and, as a public broadcaster, independent of private sector companies. Moreover, its news division is a well-resourced, epistemically sound, genuinely public communicator, as opposed to an epistemically suspect or narrowcast communicator-or platform facilitating the dissemination of epistemically suspect, narrowcast content. It is a genuinely public communicator by virtue of having a UK national and a global audience composed in part of most of the key national and international opinion makers and most of the other influential public communicators. As such, it is wellpositioned to hold governments and powerful private sector actors alike to account.

Here I note that the widely held view that the advent of the Internet and of social media platforms, such as Facebook, Google, Twitter and the like, has rendered traditional epistemic institutions, such as a free and independent press, redundant has proven to be incorrect. Contrary to this view, the advent of global social media platforms, such as Facebook, Twitter and YouTube has led, as mentioned above, to an exponential increase in the spread of fake news, hate speech and propaganda and, as a consequence has undermined the practice of rational inquiry and the existence of well-informed political perspectives among the citizenry, and done so in part by undermining epistemic norms and in part by undermining the strength and influence of epistemic institutions e.g. by enabling the dissemination of propaganda, fake news and hate speech on a vast scale. Moreover, these giant tech companies have failed to adequately self-regulate in a manner that ensures that the content on their platforms complies with epistemic norms. Indeed, the tech giants often disavow responsibility for these untoward developments by arguing that they are merely platforms and not publishers of the noxious content in question. More generally, the commercial interests of the tech giants tend in practice to override their stated commitments to the public good and, in particular, to upholding epistemic norms in respect of the content their platforms support.

There are at least four salient features of the developments just described. First, the social media platforms are in fact platforms rather than publishers. They provide communication infrastructure and, in this respect, they are akin to telephone companies. An important consequence of this is that they can escape legal liability for illegal content supported by their platforms. Second, there is the extraordinary communicative reach of the technology. Third, there is the global institutional character of the tech companies. Fourth, there is the embeddedness of these technology platforms that ought to serve the collective good in market-based institutions whose business model is to provide 'free' access in return for the provision of private data that can be exploited commercially.

What is called for at this point is a strategy for the institutional redesign of the giant tech companies. Here there are a number of guiding principles. These principles should be understood against a background assumption that the tech companies and the technology they use have provided enormous communicative and epistemic benefits and these should not be sacrificed; the baby should not be thrown out with the bathwater. In so far as the giant tech companies are to remain market-based 
companies, they need to respect the principles of free and fair competition; accordingly, they might need to be downsized to achieve this, although the presence of Chinese-based tech giants, such as Tencent and Baidu, complicates matters here. In so far as they are infrastructure providers of platforms then each must be redesigned to ensure that it provides the required public good; commercial considerations cannot be allowed to trump its provision of the public good, as is allowable in the case of an ordinary commercial enterprise considered on its own (as opposed to as one actor in a market-based industry (Miller 2010)). This may require them to be transformed into public utilities. Thirdly, regulation of content to ensure compliance with epistemic norms is a task that cannot be left to the tech giants themselves or, at least, cannot be left to them in the absence of legal liability in the circumstance that they fail adequately to ensure this compliance, i.e. in the absence of their having the legal status of publishers. Arguably, this task needs to be performed by an external, independent institution, albeit it is a task that should be paid for by the tech companies themselves and/or their advertisers or others who use their platforms. Here it is important to distinguish between holding someone and/or some organisation legally liable for publishing illegal content-and, in the absence of a publisher other than the tech giants providing the platforms, this might need to be the tech giants themselves - and ensuring the compliance of communicative content with epistemic norms by means of, for instance, an editorial process. The latter process of epistemic quality assurance includes more than ensuring that legal requirements are met. A final point concerns the business model that involves the provision of a service in return for handing over one's private information. Recent EU regulation (General Data Protection Regulation) has been enacted, among other reasons, to ensure informed consent on the part of those who might be asked to provide private information in return for a service. Such legislation might ultimately undermine this business model.

\subsection{Conclusion}

In this article, I provided definitions of fake news, hate speech and propaganda, respectively. These phenomena are corruptive of epistemic norms. I also elaborated on the right to freedom of communication and its relation both to censoring propaganda and to the role of epistemic institutions. Finally, I discussed the general problem of countering political propaganda in cyberspace and argued, firstly, that there was an important role for epistemic institutions in this regard and, secondly, that social media platforms needed to be redesigned since, as they stand and notwithstanding the benefits that they provide, they are a large part of the problem. 


\section{References}

Berger JM (2017) Defeating is propaganda. sounds good, but what does it really mean? International Centre for Counter-Terrorism - The Hague. https://icct.nl/publication/defeating-is-ideologysounds-good-but-what-does-it-really-mean/. Last access 7 July 2019

Bok S (1978) Lying: moral choice in public and private life. Pantheon Books, New York

Cocking D, van den Hoven J (2018) Evil on-line, Wiley-Blackwell, Hoboken

Ellul J (1973) Propaganda: the formation of men's attitudes (trans: Kellen K, Lerner J). Random House/Vintage, New York

Gore A (2007) The assault on reason. Penguin, New York

Grassegger VH, Krogerus M (3 Dec 2016) Ich habe nur gezeigt, dass es die Bombe gibt. Das Magazin. https://www.dasmagazin.ch/2016/12/03/ich-habe-nur-gezeigt-dass-es-die-bombegibt/. Last access 7 July 2019

Ingram HJ (2016) A brief history of propaganda during conflict. International Centre for CounterTerrorism - The Hague. https://icct.nl/publication/a-brief-history-of-propaganda-during-conflict-a-lesson-for-counter-terrorism-strategic-communications/. Last access 7 July 2019

Kant I (1956) Groundwork of the metaphysics of morals (trans: Paton HJ). Harper Collins

Lynch M (2016a) Fake news and the internet shell game. New York Times. https://www.nytimes. com/2016/11/28/opinion/fake-news-and-the-internet-shell-game.html. Last access 7 July 2019

Lynch M (2016b) The internet of us. Liveright, New York

Mill JS (1869) On liberty. Longman, Roberts and Green, London

Miller S (2000) Academic autonomy. In: Coady T (ed) Why universities matter. Allen and Unwin, St Leonards

Miller S (2010) The moral foundations of social institutions. Cambridge University Press, Cambridge

Miller S (2017) Institutional corruption. Cambridge University Press, Cambridge

Miller S (2018) Joint epistemic action: some applications. J App Philos 35(2):300-318

Schauer F (1981) Free speech: a philosophical inquiry. Cambridge University Press, Cambridge

Waldron J (2012) The harm in hate speech. Harvard University Press, Cambridge, MA

Open Access This chapter is licensed under the terms of the Creative Commons Attribution 4.0 International License (http://creativecommons.org/licenses/by/4.0/), which permits use, sharing, adaptation, distribution and reproduction in any medium or format, as long as you give appropriate credit to the original author(s) and the source, provide a link to the Creative Commons licence and indicate if changes were made.

The images or other third party material in this chapter are included in the chapter's Creative Commons licence, unless indicated otherwise in a credit line to the material. If material is not included in the chapter's Creative Commons licence and your intended use is not permitted by statutory regulation or exceeds the permitted use, you will need to obtain permission directly from the copyright holder.

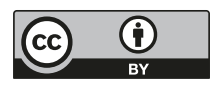

